\title{
The Combined Use of Intraluminal and Intrasaccular Flow Diversion for the Treatment of Intracranial Aneurysms: Report of 25 Cases
}

\author{
Pervinder Bhogal, MBBS', Muhammad AlMatter, MD', Victoria Hellstern, MD', \\ Oliver Ganslandt, MD³, Hansjörg Bäzner, MD², Hans Henkes, MD ${ }^{1,4}$, Marta Aguilar-Pérez, MD'
}

Purpose: The Medina Embolic Device (MED) is a new intrasaccular device with promising early results. Previously we documented our initial experience of this device both alone and in combination with other devices including flow diverter stents (FDS). We sought to determine the effect of the MED + FDS strategy for the treatment of selected aneurysms.

Materials and Methods: We performed a retrospective analysis of prospectively collected data to identify all patients with aneurysms treated using both the MED and intraluminal FDS. We present our technical success rate, early and mid-term angiographic follow-up, and clinical outcome data.

Results: We identified 25 non-consecutive patients. The treatment was staged in 9 patients and in a single session 16 patients. The average age was $61 \pm 12.8$ years (range $40-82$ ). The average fundus height was $11 \pm 3.6 \mathrm{~mm}$ and average fundus width was $10.1 \pm 3.4 \mathrm{~mm}$. In the staged cohort $(\mathrm{n}=9)$ at delayed angiography (mean 10 mths) 8 aneurysms ( $89 \%$ ) showed complete exclusion (mRRC 1) and in one patient there was a parent vessel occlusion. In the simultaneous cohort delayed angiography ( $n=10$, mean 8.1 months) demonstrated complete occlusion (mRRC 1 ) in 6 aneurysms (60\%), 3 neck remnants ( $m R R C 2)(30 \%)$ and 1 patient (10\%) showed persistent aneurysmal filling (mRRC 3a). There were 5 complications with permanent morbidity ( $m R S>2$ ) in two patients. There were no mortalities.

Conclusion: The MED can be successfully used in combination with intraluminal FDS and in selected aneurysms this may represent an alternative to FDS and adjunctive coiling.

Key Words : Intracranial aneurysm; flow diversion; Medina embolization device

${ }^{1}$ Neuroradiological Clinic, Neurocenter, Klinikum Stuttgart, Germany

${ }^{2}$ Neurological Clinic, Neurocenter, Klinikum Stuttgart, Germany

${ }^{3}$ Neurosurgical Clinic, Neurocenter, Klinikum Stuttgart, Germany

${ }^{4}$ Medical Faculty, University Duisburg-Essen, Germany

Received February 17, 2018; Revised February 23, 2018; Accepted February 26, 2018

Correspondence to: Pervinder Bhogal, MBBS

Neuroradiological Clinic, Neurocenter, Klinikum Stuttgart, Kriegsbergstrasse 60, 70174 Stuttgart, Germany

Tel. +44.781.5937220 E-mail: bhogalweb@aol.com

This is an Open Access article distributed under the terms of the Creative Commons Attribution Non-Commercial License (http://creativecommons.org/licenses/by-nc/3.0) which permits unrestricted non-commercial use, distribution, and reproduction in any medium, provided the original work is properly cited. 


\section{Luminal and saccular flow diversion}

The Medina Embolic Device (MED; Covidien/eV3, Medtronic, Dublin, Ireland) is a new generation of intrasaccular flow diverter. The device has been granted CE mark in Europe and consists of a three-dimensional layered structure made from a radiopaque shape set core wire, and shape memory alloy filaments, which form a self-expanding mesh. Although there is limited experience of the device the available evidence suggests that it has a good safety profile and there is a negligible learning curve. ${ }^{1-3}$

In our previous publication we documented the use of the MED both alone and in conjunction with other devices such as standard intraluminal flow diverters. ${ }^{3}$ In this publication we documented the potential shortcomings of the MED when used as a stand-alone device however, we suggested that the device if used in combination with other devices may allow for extremely rapid occlusion of aneurysms, especially large aneurysms.

In this paper we document our experience on use of the MED with intraluminal flow diversion both sequentially and simultaneously using a jailing technique. We discuss the potential advantages of this technique and provide early follow-up on the use of both intraluminal and intrasaccular flow diversion in combination.

\section{MATERIALS AND METHODS}

\section{Patient selection}

We retrospectively searched our prospectively maintained database to identify patients treated with both the MED and an intraluminal flow diverter stent (FDS) between September 2015 and September 2017.

\section{Endovascular treatment}

We offered the use of MED to selected patients with unruptured aneurysms with a fundus diameter of $\geq 5$ $\mathrm{mm}$. The decision was based on individual aspects such as anticipated feasibility of this kind of treatment, propensity to coil compaction or aneurysm reperfusion. Patient informed consent was obtained before the procedure in all cases. All treatments were performed under general anaesthesia.

All patients received dual antiplatelet therapy (aspirin $100 \mathrm{mg}$ daily and clopidogrel $75 \mathrm{mg}$ daily) for at least five days prior to the treatment. The effectiveness of the antiplatelet regime was tested using the Multiplate analyser (Roche, Basel, Switzerland) and since 2016 the VerifyNow test (Accumetrics, San Diego, CA, USA) was also used. Patients found resistant to clopidogrel received $2 \times 90 \mathrm{mg}$ ticagrelor daily. The post-procedural antiplatelet regimen consisted of clopidogrel (or ticagrelor) continued for 12 months following treatment and aspirin continued for life.

Procedures were performed via the right common femoral route using a $6 \mathrm{Fr}$ access system as standard. For deployment of the MED a 0.021" ID Prowler Select Plus (Codman, Raynham, MA, USA) microcatheter was used. The framing MED was chosen based on a similar sizing method used for standard coils. In spherical saccular aneurysms with a fundus diameter of 9 $\mathrm{mm}$ or less the size of the first framing MED was purposely undersized by about $1 \mathrm{~mm}$. After forming a spherical shape and adequate positioning of the framing MED it was mechanically detached and the requirement for further occlusion was assessed. Two commercially available intraluminal FDS were used: the Pipeline Embolisation Device (PED) (Covidien, Irvine, CA, USA) and p64 (phenox, Bochum, Germany). The selection of FDS was dependent upon the operators' judgement.

For deployment of the intraluminal flow diverter either a Marksman (Medtronic, Dublin, Ireland) catheter or an Excelsior XT27 (Stryker Neurovascular, Kalamazoo, MI, USA) catheter was used. In cases where a jailing technique was used the aneurysm was first catheterised followed by partial deployment of the intraluminal FDS to cover the neck. The MED was then deployed with the neck protection provided by the intraluminal FDS. After deployment of the MED the intraluminal FDS was fully deployed and detached.

All procedures were performed under heparin anticoagulation with a $5000 \mathrm{IU}$ bolus dose at the start of the procedure and subsequent $1000 \mathrm{IU}$ bolus doses every hour to maintain the activated clotting time between 22.5 times the baseline.

\section{Procedural assessment and follow-up}

Patency and flow characteristics within the aneurysm was assessed angiographically immediately after placement of the MED and the FDS and during followup. Procedural follow-up with digital subtraction angiography (DSA) is routinely performed initially at 3-6 months, again at 9-12 months and then once per year usually for three years or until the aneurysm was excluded from the circulation. In our early experience with the MED very early DSA follow-up was performed within the first two weeks.

Standard angiographic projections were used to assess the patency of the vessels and the aneurysms in addition to angiographic projections that repeated those used during the treatment. Aneurysm occlusion was 
graded using the modified Raymond-Roy classification $(\mathrm{mRRC})^{4}$ or unchanged (patent).

\section{RESULTS}

We identified 25 patients, 21 of which were female (84\%) with 25 aneurysms that were treated with the MED and FDS. The average age of the patients was 61 \pm 12.8 years (range $40-82$ ). Eleven aneurysms were located on the left, one aneurysm was in the midline the remaining 13 aneurysms were on the right.

Aneurysm location was the para-ophthalmic segment of the ICA $(n=8)$, the cavernous ICA $(n=4)$, the supraclinoidal segment $(n=3)$, posterior communicating artery $(n=5)$, ICA bifurcation $(n=1)$, the M1 segment $(\mathrm{n}=1)$, the A1 segment $(\mathrm{n}=2)$, and anterior communicating artery $(\mathrm{n}=1)$.

The average dome height was $11 \pm 3.6 \mathrm{~mm}$ (range 5.9-17.2 mm), average dome width was $10.1 \pm 3.4 \mathrm{~mm}$ (range $6-17.5 \mathrm{~mm}$ ) and average neck width was $5.6 \pm$

Table. 1. Aneurysm size, location, and clinical presentation

\begin{tabular}{|c|c|c|c|c|c|c|c|c|}
\hline \multicolumn{9}{|c|}{ Aneurysm Characteristics } \\
\hline $\begin{array}{l}\text { Patient } \\
\text { Number }\end{array}$ & Location & Laterality & $\begin{array}{l}\text { Neck width } \\
(\mathrm{mm})\end{array}$ & $\begin{array}{l}\text { Fundus width } \\
\qquad(\mathrm{mm})\end{array}$ & $\begin{array}{l}\text { Fundus height } \\
\qquad(\mathrm{mm})\end{array}$ & $\begin{array}{l}\text { Aspect } \\
\text { ratio }\end{array}$ & $\begin{array}{l}\text { Bottle neck } \\
\text { factor }\end{array}$ & Presentation \\
\hline 1 & Paraophthalmic & $\mathrm{L}$ & 3.5 & 8.5 & 6.5 & 1.9 & 2.4 & Incidental \\
\hline 2 & PcomA & $\mathrm{L}$ & 5 & 9 & 11.2 & 2.2 & 1.8 & Incidental \\
\hline 3 & AcomA & Midline & 4.5 & 8 & 9 & 2.0 & 1.8 & Incidental \\
\hline 4 & ICA bifurcation & $\mathrm{R}$ & 4 & 6 & 6.3 & 1.6 & 1.5 & Incidental \\
\hline 5 & Paraophthalmic & $\mathrm{R}$ & 6.6 & 9 & 12 & 1.8 & 1.4 & Incidental \\
\hline 6 & Cavernous & $\mathrm{R}$ & 8 & 16 & 16 & 2.0 & 2.0 & Incidental \\
\hline 7 & Paraophthalmic & $\mathrm{R}$ & 3.8 & 7 & 5.9 & 1.6 & 1.8 & Incidental \\
\hline 8 & PcomA & $\mathrm{R}$ & 3.9 & 6 & 11.5 & 2.9 & 1.5 & Incidental \\
\hline 9 & Cavernous & $\mathrm{R}$ & 6 & 10 & 10 & 1.7 & 1.7 & Incidental \\
\hline 10 & Paraophthalmic & L & 5 & 12.6 & 17.2 & 3.4 & 2.5 & Incidental \\
\hline 11 & Paraophthalmic & $L$ & 7.7 & 9 & 11 & 1.4 & 1.2 & Incidental \\
\hline 12 & Supraclinoid & $\mathrm{L}$ & 4 & 10.8 & 13.6 & 3.4 & 2.7 & Incidental \\
\hline 13 & MCA, M1 & $\mathrm{R}$ & 7.6 & 11.3 & 14.1 & 1.9 & 1.5 & Incidental \\
\hline 14 & Paraophthalmic & $L$ & 9.7 & 15.5 & 15.5 & 1.6 & 1.6 & Mass effect \\
\hline 15 & PcomA & $\mathrm{L}$ & 4.5 & 8.6 & 9.4 & 2.1 & 1.9 & Incidental \\
\hline 16 & $\mathrm{~A} 1$ & $L$ & 8.5 & 9.4 & 14.5 & 1.7 & 1.1 & Mass effect \\
\hline 17 & PcomA & $\mathrm{R}$ & 2 & 5 & 9.4 & 4.7 & 2.5 & Incidental \\
\hline 18 & Cavernous & $\mathrm{L}$ & 5 & 16.2 & 13.6 & 2.7 & 3.2 & Mass effect \\
\hline 19 & Cavernous & $\mathrm{R}$ & 6 & 9.3 & 6.8 & 1.1 & 1.6 & Incidental \\
\hline 20 & Paraophthalmic & $\mathrm{R}$ & 4.6 & 6.5 & 7.8 & 1.7 & 1.4 & Incidental \\
\hline 21 & Supraclinoid & $\mathrm{R}$ & 7.5 & 9.5 & 8 & 1.1 & 1.3 & Incidental \\
\hline 22 & Supraclinoid & $\mathrm{R}$ & 7 & 8.5 & 7.8 & 1.1 & 1.2 & Incidental \\
\hline 23 & PcomA & $\mathrm{L}$ & 4.5 & 13.3 & 16 & 3.6 & 3.0 & Incidental \\
\hline 24 & Paraophthalmic & $\mathrm{R}$ & 4.6 & 9.5 & 7 & 1.5 & 2.1 & Incidental \\
\hline 25 & A1 & $\mathrm{L}$ & 6 & 17.5 & 15 & 2.5 & 2.9 & Incidental \\
\hline
\end{tabular}

PcomA, posterior communicating artery; AcomA, anterior communicating artery; ICA, internal carotid artery; MCA, middle cerebral artery; $R$, right; $L$, left

Aspect ratio defined as fundus height-to-neck width and bottleneck ratio defined as fundus width-to-neck width. 


\section{Luminal and saccular flow diversion}

$1.8 \mathrm{~mm}$ (range $2-9.7 \mathrm{~mm}$ ). The average aspect ratio was 2.1 and the average bottleneck ratio was 1.9. Three of the aneurysms presented with mass effect symptoms and the remaining were incidental. The aneurysm characteristics are summarised in Table 1.

\section{Sequential Treatment}

In total nine patients were treated sequentially with MED's placed in the aneurysm and then at a later date an intraluminal FDS was implanted (Fig. 1). An average of 4.3 (range 1-9) MED's were placed in each aneurysm and a single FDS was implanted to treat eight of the aneurysms. At the end of the MED implantation three patients had persistent neck remnants (mRRC 2) and the remaining six patients demonstrated persistent filling of the aneurysm sac (mRRC 3a). The FDS was implanted at an average of 1.6 months (range $0.25-7$ months) after the MED's were implanted. Two intraluminal FDS were implanted in a single patient. The p64 FDS was used in all cases.

At initial follow-up performed on average two months after implantation of the FDS (range $0.5-3$ months) four aneurysms showed complete exclusion (mRRC 1), four showed neck remnants (mRRC 2) and one parent vessel occlusion had occurred. At the last follow-up performed on average 10 months (range 715 months) after the initial treatment eight aneurysms showed complete exclusion of the aneurysm. The results are summarised in Table 2.

\section{Simultaneous Procedure including Jailing Technique}

In total 16 patients the aneurysms were treated with MED and an intraluminal FDS during the same treatment session. In four cases a jailing technique (Fig. 2) was used and in 12 cases the MED's were placed and detached inside the aneurysm followed by deployment of the intraluminal FDS (Fig. 3). An average of 3.9 MED's were deployed (range 1-13) and an average of 1.2 intraluminal FDS were placed (range $1-4)$. The p64 was used alone in 14 cases, the p48 in one case and a PED was used in conjunction with the
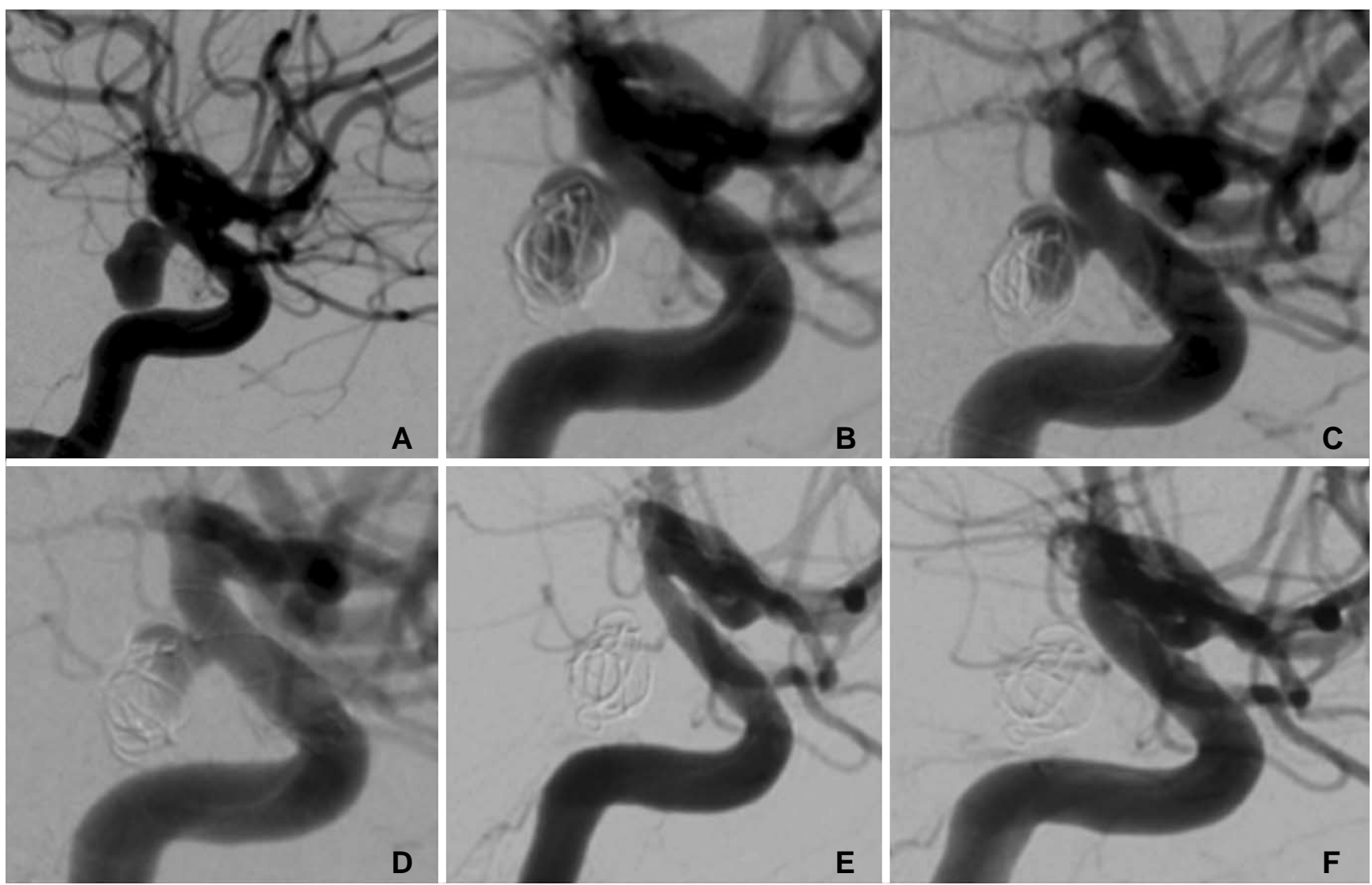

Fig. 1. A patient in their 30's with an unruptured incidental right PComA aneurysm that measured $9 \times 5 \mathrm{~mm}(\mathbf{A})$. At the initial treatment two MED's were placed in the aneurysm sac and at the end of the procedure sub-total opacification of the aneurysm was seen (B). At initial follow-up (one month) there was a significant neck remnant and filling of the proximal fundus (C). At this stage a single p64 FDS was implanted (D). Follow-up three months after implantation of the FDS showed complete exclusion of the aneurysm from the circulation (mRRC 1) and mild, asymptomatic, in-stent stenosis $(\mathbf{E})$ that spontaneously resolved on delayed angiography $(\mathbf{F})$. 


\section{Pervinder Bhogal, et al.}

p64 in one case.

Initial follow-up angiography was available for 13 aneurysms. One patient had an occlusion of the FDS at four months. Of the remaining 12 aneurysms angiography was performed on average at 2.8 months postprocedure, six (50\%) aneurysms showed complete

Table 2. Clinical and radiographic outcome of patients treated using a staged method

\begin{tabular}{|c|c|c|c|c|c|c|c|c|c|c|}
\hline $\begin{array}{l}\text { Patient } \\
\text { Number }\end{array}$ & $\begin{array}{c}\text { Number } \\
\text { of } \\
\text { MED's }\end{array}$ & $\begin{array}{c}\text { mRRC } \\
\text { post } \\
\text { MED }\end{array}$ & $\begin{array}{c}\text { Type+ } \\
\text { Number } \\
\text { of FDS }\end{array}$ & $\begin{array}{c}\text { Time between } \\
\text { MED and FDS } \\
\text { (months) }\end{array}$ & $\begin{array}{l}\text { Initial follow-up } \\
\text { (months) after } \\
\text { MED+FDS }\end{array}$ & $\mathrm{mRRC}$ & $\begin{array}{l}\text { Delayed } \\
\text { follow-up } \\
\text { (Months) }\end{array}$ & $\begin{array}{c}\text { Delayed } \\
\text { mRRC }\end{array}$ & Complications & $\mathrm{mRS}$ \\
\hline 1 & 1 & $3 a$ & 1 p64 & 1 & 3 & 1 & 7 & 1 & & 0 \\
\hline 2 & 3 & $3 a$ & 1 p64 & 1.5 & 1.5 & 2 & 7 & 1 & & 0 \\
\hline 3 & 2 & $3 a$ & 1 p64 & 1.5 & 1.5 & 2 & 10 & 1 & & 0 \\
\hline 8 & 5 & 2 & 2 p64 & 0.5 & 1 & 2 & 15 & 1 & & 0 \\
\hline 9 & 9 & $3 a$ & 1 p64 & 7 & 3 & 1 & 10 & 1 & & 0 \\
\hline 12 & 5 & $3 a$ & $1 \mathrm{p} 64$ & 0.5 & 0.5 & 2 & 10 & 1 & & 0 \\
\hline 15 & 6 & 2 & $1 \mathrm{p} 64$ & 0.5 & 3 & 1 & 10 & 1 & & 0 \\
\hline 16 & 6 & 2 & $1 \mathrm{p} 64$ & 0.25 & NA & NA & 9 & 1 & $\begin{array}{l}\text { Occlusion of the } \\
\text { FDS after } 6 \text { days }\end{array}$ & 1 \\
\hline 17 & 2 & $3 a$ & $1 \mathrm{p} 64$ & 1 & 2 & 1 & 9 & 1 & & 0 \\
\hline
\end{tabular}

MED, Medina Embolic Device; FDS, Flow Diverter Stent; mRRC, modified Raymond Roy Classification; mRS, modified Rankin Score
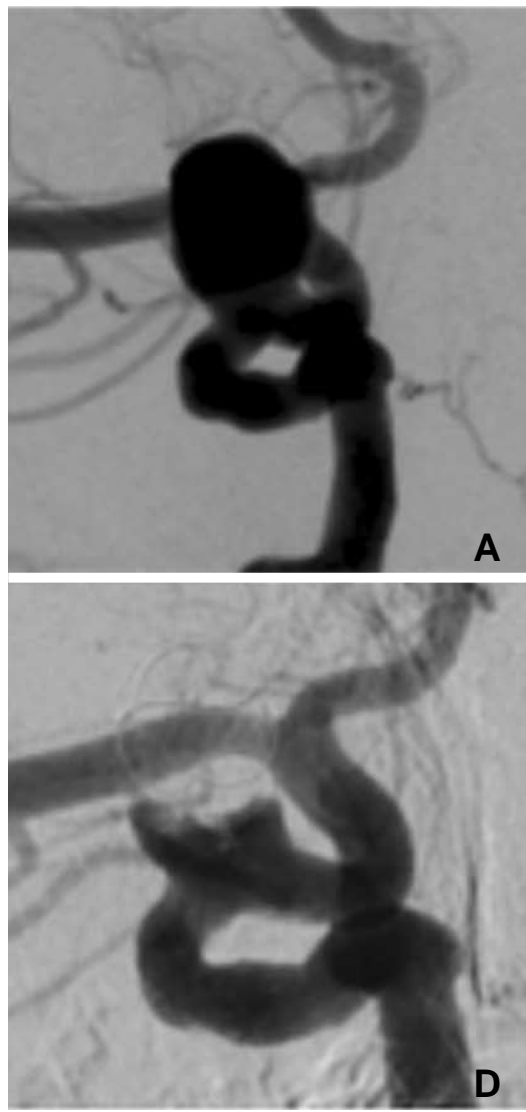
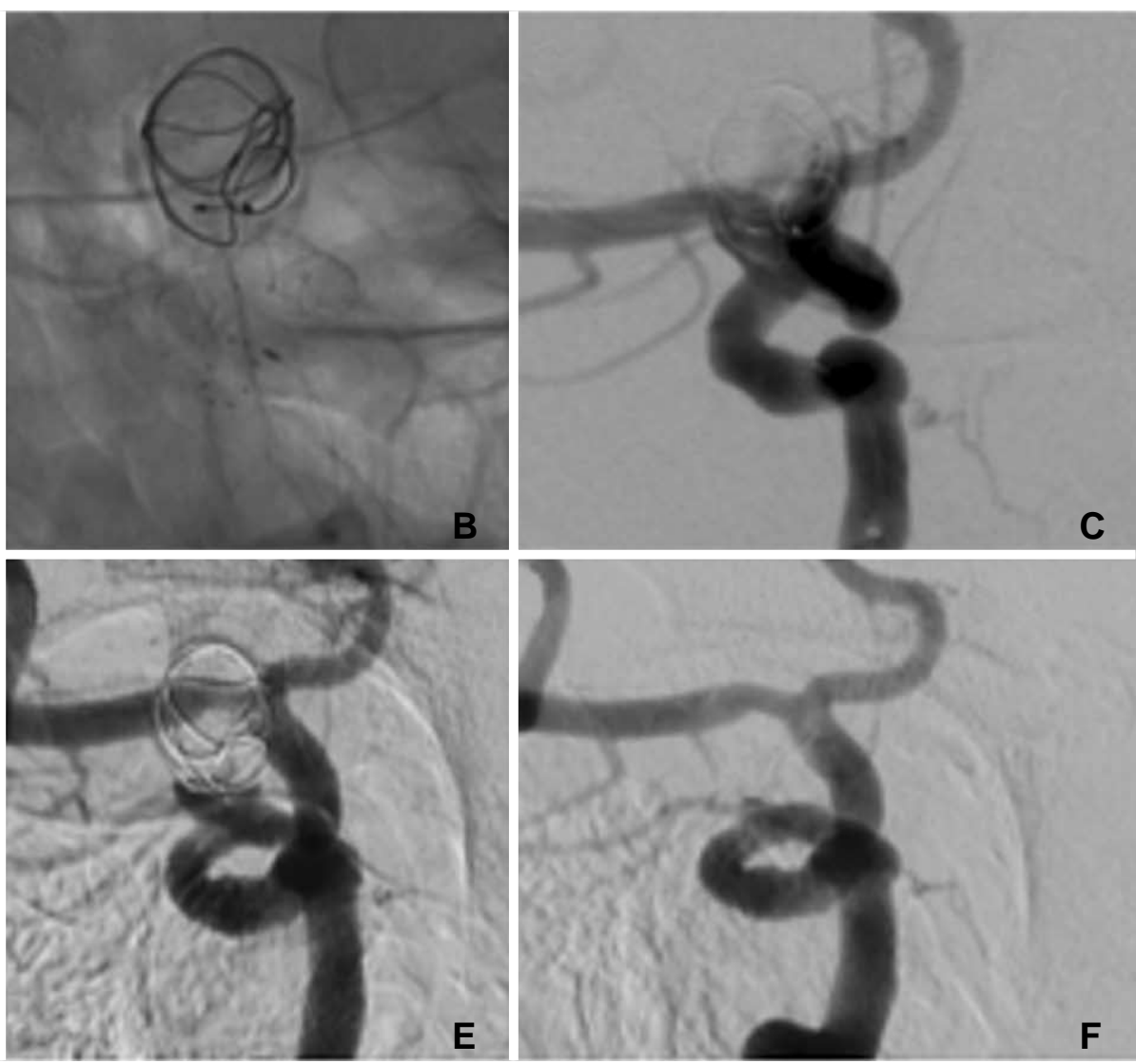

Fig. 2. A patient in their 70's with an incidental $9 \times 12 \mathrm{~mm}$ para-ophthalmic aneurysm (A) was treated initially with a MED with a p64 FDS deployed during the same procedure $(\mathbf{B})$. At the end of the procedure there was persistent filling of the aneurysm (C). Early follow-up angiography (two months post-procedure) showed a persistent neck remnant (D), which gradually decreased over time (E). At delayed angiography (eight months) there is complete exclusion of the aneurysm from the circulation (mRRC I) (F). 


\section{Luminal and saccular flow diversion}
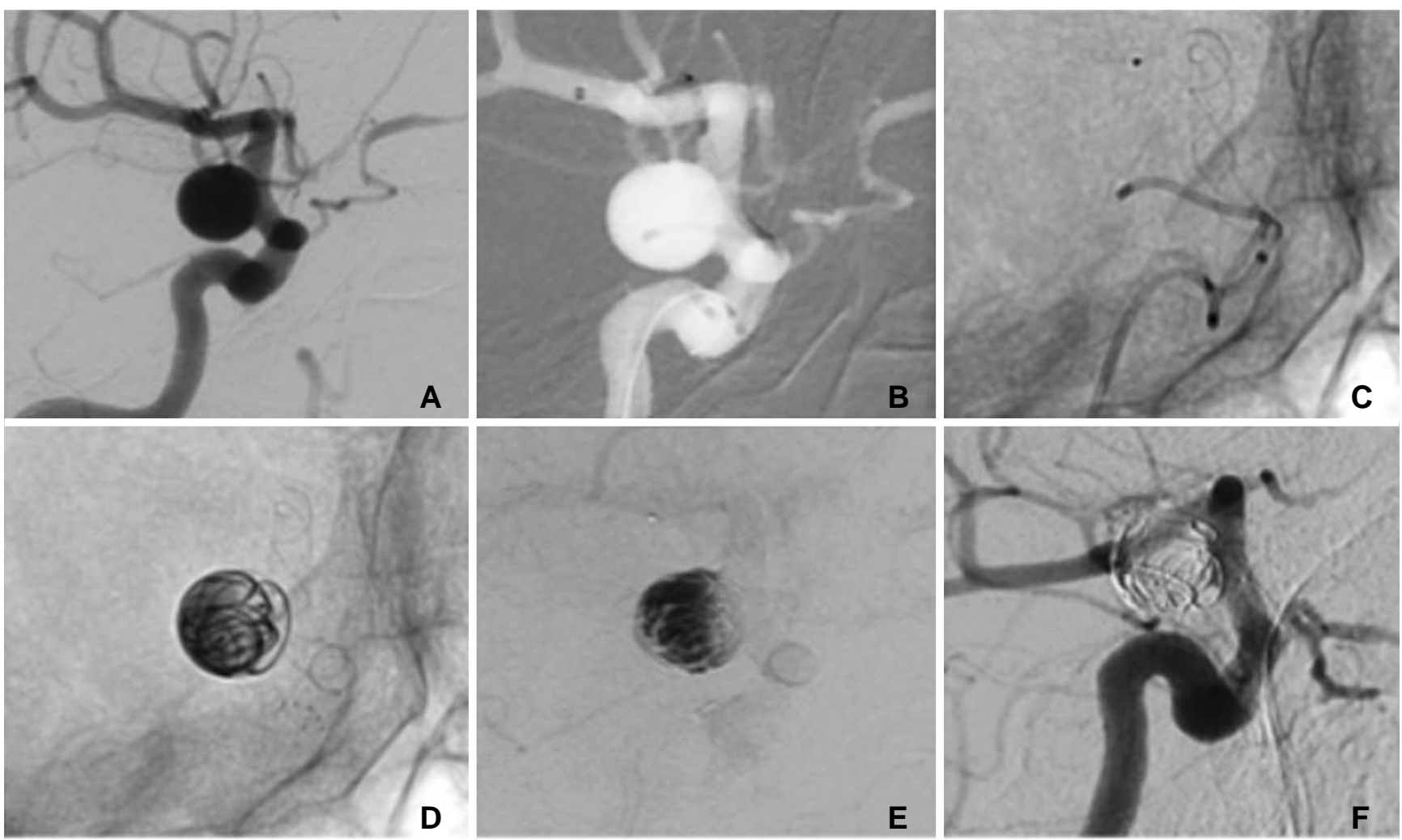

Fig. 3. A patient in their 70's with an incidental $8 \times 8 \mathrm{~mm}$ of the supraclinoid ICA (A) was treated with the MED and a p64 FDS using a jailing technique. After the catheterisation of the aneurysm and the M1 segment (B) the p64 was partially deployed until it completely covered the neck of the aneurysm (C). Subsequently, three MED's were deployed in the aneurysm (D) and the p64 was fully deployed and detached. Angiography at the end of the procedure showed marked contrast stagnation within the aneurysm (E). Angiography performed seven months post-procedure demonstrated complete exclusion of the aneurysm from the circulation (mRRC 1) (F).

occlusion (mRRC 1), three aneurysms $(25 \%)$ showed neck remnants (mRRC 2), and the remaining three patients $(25 \%)$ showed persistent but subtotal filling of the aneurysm fundus (mRRC $3 a)$.

Delayed angiographic follow-up was available in 10 patients and performed on average 8.1 months after the procedure at which point six aneurysms $(60 \%)$ showed complete occlusion of the aneurysm (mRRC 1), three aneurysms showed neck remnants (30\%) showed neck remnants (mRRC 2) and one patient (10\%) showed persistent filling of the aneurysm fundus (mRRC $3 a$ ). The results are summarised in Table 3.

\section{Complications}

There were five complications, two of which led to permanent morbidity. There were no cases of mortality.

In three patients there was thrombosis within the FDS. In one patient this was asymptomatic (patient 16). Patient 6 developed an in-stent thrombus four months after the patient inadvertently stopped taking their prescribed anti-platelet medication. The patient was successfully treated with mechanical thrombec- tomy was left with permanent morbidity (mRS 4). In patient 7 in-stent thrombosis occurred five days postprocedure. The patient was successfully treated with mechanical thrombectomy and returned to baseline neurology ( $\mathrm{mRS} 0)$. In one patient there was an asymptomatic sub-arachnoid haemorrhage, detected on routine post-operative imaging, the cause of which was unknown. In patient 23 after deployment of the MED, a MED coil loop protruded into the parent artery prior to the implantation of the FDS. The patient had been placed on dual antiplatelet medication prior to the operation however, a bolus dose of eptifibatide was given. Post-operatively there was a large intraparenchymal haemorrhage that was thought to be due to haemorrhagic conversion of an ischaemic lesion.

\section{DISCUSSION}

The MED represents a major advancement in the design of endosaccular flow diverters. In the first publication on the use of the MED, Turk et al. ${ }^{2}$ included nine patients, seven of whom were treated solely with 
Pervinder Bhogal, et al.

Table 3. Clinical and radiographic outcome of patients treated with MED and FDS in the same sitting

\begin{tabular}{|c|c|c|c|c|c|c|c|c|c|c|}
\hline $\begin{array}{l}\text { Patient } \\
\text { Number }\end{array}$ & $\begin{array}{l}\text { Number } \\
\text { of MED's }\end{array}$ & $\begin{array}{c}\text { Type and } \\
\text { Number of } \\
\text { FDS }^{+}\end{array}$ & $\begin{array}{c}\text { Jailing } \\
\text { Technique }\end{array}$ & $\begin{array}{c}\text { Immediate } \\
\text { post-op } \\
\text { mRRC }\end{array}$ & $\begin{array}{c}\text { Initial } \\
\text { follow-up } \\
\text { (months) }\end{array}$ & $\mathrm{mRRC}$ & $\begin{array}{l}\text { Delayed } \\
\text { follow-up } \\
\text { (months) }\end{array}$ & $\mathrm{mRRC}$ & Complications & $\mathrm{mRS}$ \\
\hline 4 & 1 & $1 \mathrm{p} 64$ & $\mathrm{~N}$ & $3 a$ & 1.5 & 3 & 301 & 1 & & 0 \\
\hline 5 & 1 & 1 p64 & $\mathrm{N}$ & $3 a$ & 1.5 & 2 & 257 & 1 & & 0 \\
\hline 6 & 4 & 1 p64 & Y & $3 a$ & 10.5 & 1 & 463 & 1 & $\begin{array}{l}\text { Occlusion of the } \\
\text { FD after } 4 \text { months }\end{array}$ & 4 \\
\hline 7 & 1 & 1 p64 & $\mathrm{N}$ & $3 a$ & 2.5 & 1 & 284 & 1 & $\begin{array}{l}\text { Occlusion of the } \\
\text { FD after } 5 \text { days }\end{array}$ & 0 \\
\hline 10 & 9 & 1 p64 & $\mathrm{N}$ & $3 a$ & 2 & 2 & 392 & 2 & & 0 \\
\hline 11 & 2 & 1 p64 & $\mathrm{Y}$ & $3 a$ & 3 & 1 & 288 & 1 & & 0 \\
\hline 13 & 1 & 1 p64 & $\mathrm{N}$ & $3 a$ & 3 & 3 & 299 & 2 & & 0 \\
\hline 14 & 6 & $1 \mathrm{p} 64$ & $\mathrm{~N}$ & $3 a$ & 3 & 1 & 325 & 1 & & $1^{*}$ \\
\hline 18 & 10 & 3 p64, 1 PED & $\mathrm{N}$ & $3 a$ & 2.5 & 3 & 291 & 2 & & $2^{*}$ \\
\hline 19 & 1 & $1 \mathrm{p} 64$ & $\mathrm{~N}$ & $3 a$ & 3 & 1 & 267 & 1 & & 0 \\
\hline 20 & 1 & $1 \mathrm{p} 64$ & $\mathrm{~N}$ & $3 a$ & 3 & 2 & 249 & 2 & $\mathrm{SAH}$ - asymptomatic & $c 0$ \\
\hline 21 & 2 & $1 \mathrm{p} 64$ & Y & $3 a$ & 4.5 & 1 & 136 & 2 & & 0 \\
\hline 22 & 3 & 1 p64 & Y & $3 a$ & 3 & 1 & 90 & 1 & & 0 \\
\hline 23 & 13 & $1 \mathrm{p} 64$ & $\mathrm{~N}$ & $3 a$ & NA & NA & NA & NA & $\mathrm{ICH}$ & 4 \\
\hline 24 & 1 & 1 p64 & $\mathrm{N}$ & $3 a$ & NA & NA & NA & NA & & 0 \\
\hline 25 & 7 & $1 \mathrm{p} 48$ & $\mathrm{~N}$ & $3 a$ & NA & NA & NA & NA & & 0 \\
\hline
\end{tabular}

MED, Medina Embolic Device; FDS, Flow Diverter Stent; mRRC, modified Raymond Roy Classification; mRS, modified Rankin Score; $\mathrm{NA}$, not applicable; $\mathrm{SAH}$, subarachnoid haemorrhage; $\mathrm{ICH}$, intracerebral hematoma

* there was no change between the pre-operative and post-operative mRS.

the MED with aneurysms varying in size from $4.5 \mathrm{~mm}$ to $17 \mathrm{~mm}$. Only three of the aneurysms had early follow-up at one month, all three showed $>95 \%$ occlusion and the authors state that this limited followup provided an early indication that the device caused progressive aneurysm occlusion over time.

In our own publication on the use of the $\mathrm{MED}^{3}$ we presented the results of 15 consecutive patients with 16 aneurysms were reported. In this series 3.4 MED's per aneurysm were used (range 1-9). Adjunctive devices were used to treat several of the aneurysms. In this original publication we discussed in detail the potential advantages and disadvantages of the device including the problems regarding aneurysmal shape. The MED is designed to form a spherical shape however, many aneurysms are not spherical ${ }^{5}$ which could create a problem regarding the applicability of the device to many aneurysms. The device can and has been used in non-spherical aneurysms $\mathrm{s}^{2,3}$ and can cause flow disruption however, the exact shape of the MED in the aneurysm may be difficult to assess. This difficulty in assessing the position of the leaflets of the MED within the aneurysm comes from the fact that these leaflets are almost radiolucent, even when using magnified exposures. Therefore, it can be difficult to determine the positioning of the leaflets particularly at the neck of the aneurysm. The most recent publication regarding the $\mathrm{MED}^{1}$ evaluated twelve patients with 13 aneurysms. In this series the authors used a single MED framer to obtain a basket in $12 / 13$ aneurysms. They then proceeded to implant further MED fillers, standard coils or both. The authors state that, as this was their first experience with the device, even if total exclusion of the aneurysm was seen coils were used to fill the basket in order to prevent any retraction of the MED.

The introduction of intraluminal FDS represented a major advancement in the management of intracranial aneurysmal disease that allowed not only the occlusion of aneurysms but also the reconstruction of the parent artery. Intraluminal FDS are likely to promote the 


\section{Luminal and saccular flow diversion}

occlusion of aneurysms via a combination of effects. Initially intra-aneurysmal flow alteration promotes thrombosis however, the complete exclusion of the aneurysm from the circulation does not occur until after neointima has covered the neck of the aneurysm..$^{6-10}$ The intra-aneurysmal thrombosis will depend on the flow conditions created within the aneurysm after implantation of an intra-aneurysmal FDS. Aneurysm morphology, aneurysm location, neck size, angulation and many other factors may play a role in determining the inflow stream into the aneurysm. Similarly, the individual characteristics of flow diverters and the implantation strategy e.g. compressed, appropriately sized etc. will also play a role in the intra-aneurysmal haemodynamic flow post-operatively. Pereira et al. ${ }^{11}$ used dynamic DSA images to estimate the mean aneurysm flow velocity (mean aneurysm flow amplitude, MAFA) before and after FDS treatment. They demonstrated a larger decrease in mean aneurysm flow in patients that had occluded aneurysms at follow-up compared to those in whom the aneurysms remained patent. Other investigators have reported similar results of attenuated inflow and aneurysm occlusion ${ }^{12,13}$ and in clinical cases the average reduction in intra-aneurysmal flow is in the region of $50-60 \% .{ }^{14-22}$ Although there have been no studies looking at the MAFA ration with intrasaccular flow diverting devices recent bench side studies have demonstrated that coverage at the neck is extremely important. Frolich and colleagues ${ }^{23}$ assessed the MED in aneurysm models. They showed that the degree of intra-aneurysmal flow disruption significantly correlated with the neck coverage $(\mathrm{P}=0.002)$ and the size of the neck $(\mathrm{P}=0.024)$. This data goes some way to confirming the clinical suspicion raised by others. ${ }^{24,25}$

This process of aneurysm exclusion post FDS occurs gradually over time and the in the recent meta-analysis of Brinjikji et al. ${ }^{26}$ the complete aneurysm occlusion rate of aneurysms treated with intraluminal FDS was $76 \%$ at 6 months. The occlusion rate was slightly higher for small aneurysm $(<10 \mathrm{~mm})$ at $80 \%$ and $74 \%$ for large aneurysms $(>10 \mathrm{~mm})$. In a more recent metaanalysis of Zhou et al. ${ }^{27}$ that looked at the results of 59 studies and the treatment of 2263 patients with 2493 aneurysms a 6 month occlusion rate of $80.1 \%$ was documented that rose $90.8 \%$ at longer term follow-up (>12 months). Whilst these results are impressive approximately $10 \%$ of aneurysms will remain patent at 12 months and therefore, there is a potential risk posed by these aneurysms. Delayed aneurysm rupture post intraluminal FDS is well documented ${ }^{28,29}$ and in a recent meta-analysis of 53 studies 81 cases of delayed aneurysms rupture were reported. ${ }^{30}$ The authors found that in cases when the rupture was documented the majority of cases or delayed rupture occurred within the first 1 month after the treatment $(77.58 \%)$. The majority of the delayed ruptured aneurysms, as would be expected, were located in the anterior circulation and the majority of the aneurysms were not giant aneurysms $(53.7 \%$ of the aneurysms $<25 \mathrm{~mm})$. This result was similar to the results of the IntrePED study where $3 / 5$ spontaneous ruptures occurred in giant aneurysms. ${ }^{31}$ The outcome in cases of delayed rupture was poor with just under $75 \%$ of delayed aneurysm ruptures resulting in death. The exact mechanism behind the delayed aneurysm rupture is incompletely understood. Some studies have demonstrated that intraaneurysmal flow changes post FDS implantation may result in either an increase in intra-aneurysmal pressure $^{32}$ or no significant decrease in pressure. ${ }^{21}$ Shobayashi et al. ${ }^{21}$ suggested that because of the persistent intra-aneurysmal pressure contrast stagnation or even the immediate disappearance of the aneurysm on post-treatment angiography does not necessarily mean that the aneurysm is protected against rupture. Other studies have suggested a potential role for intraaneurysmal thrombus as a source for proteolytic enzymes that can break down the arterial wall and result in rupture..$^{33}$ It has also been shown recently that flow conditions within the aneurysm lumen are associated with differences in aneurysm wall histology. ${ }^{34}$ It is not entirely inconceivable that based on the preoperative flow conditions certain aneurysms will not favour treatment with flow diversion alone due to the dramatic change in intra-aneurysmal flow induced by the FDS. However, this is yet to be ascertained.

In order to try and minimise the risk of delayed rupture, especially in large or giant aneurysms, concomitant coiling has been recommended by several authors. ${ }^{28,35,36}$ Of note, $20 \%$ of the delayed ruptures in the meta-analysis of Rouchaud et al. ${ }^{30}$ occurred in aneurysms that were coiled. Unfortunately the packing density of the coiling was not recorded and therefore, further analysis is difficult however, it was suggested that a higher packing density might protect against rupture.

In order to quantify the different effects of FDS, coiling and FDS + Coiling Damiano et al. ${ }^{37}$ used finite element modelling and computational fluid dynamics (CFD) to compare the intra-aneurysmal haemodynamics of coiling, of various packing density, single FDS, multiple overlapping FDS, and FDS + coiling. This study showed that coils disrupt and impinge the inflow 


\section{Pervinder Bhogal, et al.}

jet and that with increasing packing density (PD) there is decreased flow penetration into the aneurysm. A single FDS did not disrupt the vortex-like flow pattern but it does decrease the velocity of the inflow jet and of the impingement of the jet on the aneurysm wall. A single FDS accomplished a greater inflow rate reduction than coiling $(\mathrm{PD}<30 \%)$ however, coils at $\mathrm{PD}>30 \%$ results in a greater reduction in aneurysmaveraged inflow velocity than a single FDS. The adjunctive use of coils, upto a PD of $30 \%$, in addition to a single FDS reduces average intra-aneurysmal velocity and wall shear stress (WSS) beyond that achieved by a single FDS alone. However, the addition of coils produced no further inflow rate reduction until the PD exceeded $11 \%$. At low PD, $<11 \%$, the coils may act as a scaffold for intra-aneurysmal thrombus but they will have a limited haemodynamic effect. Similar additive effects of FDS and coiling have been seen by other groups. ${ }^{18}$ These studies may help to explain why even with adjunctive coiling some aneurysms rupture ${ }^{29}$ as well as the higher occlusion rate and lower risk of retreatment seen in patients treated with both FDS and coils compared to FDS alone ${ }^{38}$ since it is likely that a threshold of coil PD is necessary to achieve a meaningful clinical effect.

Although the work of Frohlich ${ }^{23}$ did not compare the MED with standard coiling we believe that the flow disrupting effect of a single MED is likely to be significantly greater than that of a single coil. This is likely to reduce the inflow velocity as well as intra-aneurysmal flow characteristics that will protect the wall and promote thrombosis. Furthermore, the MED leaflets may provide a greater stabilisation of thrombus within an aneurysm as well as greater attenuation of the WSS due to their larger surface. We believe that this combination treatment may be particularly useful in partially thrombosed aneurysms. The flow redirection effect of the intraluminal FDS and the flow disrupting effect of the intrasaccular MED, along with the more even distribution of force afforded by the MED leaflets, may prevent the device being engulfed in the thrombus as may happen with coils.

Although in-stent thrombosis was seen in several of our cases we do not believe that there is an increase in the thromboembolic risk from this technique. In one of these cases this was caused by the patient inadvertently stopping their anti-platelet medications. In the other two cases the exact cause for the in-stent thrombosis was unknown although it is know that other medications can alter the effectiveness of anti-platelet agents. ${ }^{39}$ We test all patients for anti-platelet activity prior to the implantation of FDS however, it is impossible to monitor the response of patients post-operatively and we believe that it is imperative for the general physicians to be aware of possible drug interactions with the commonly used anti-platelet medications. Similarly, although more complications occurred in the 'simultaneous' treatment cohort we do not believe that this technique is inherently more dangerous. This technique is similar to stent assisted coiling which has been shown to have a similar safety profile to standard coiling ${ }^{40}$ however, larger studies are required to prove the technique is safe. As with wide necked aneurysms, jailing with the FDS may provide security and prevent the MED's from prolapsing into the parent vessel. However, it is possible that jailed microcatheter does not allow the intraluminal FDS to properly open and abut the arterial wall. This is a hypothetical risk and not something we have seen but we do believe it could occur and therefore, careful assessment of the FDS at the end of the procedure is required. When the aneurysm neck is relatively narrow, but the aneurysm is non-spherical, it may be more appropriate to deploy the MED's followed by the FDS but not use a jailing technique as it is not required.

We believe this is the first paper to look at the combination of intraluminal and intrasaccular flow diversion. Although these results are preliminary we believe that the additive effects of these two strategies may promote safe occlusion of aneurysms, particular large aneurysms that may otherwise carry inherently greater risk of rupture post FDS implantation. We believe aneurysms best suited to this treatment strategy include large aneurysms $(>10 \mathrm{~mm})$, multi-lobulated aneurysms and non-spherical aneurysms where there is a risk of a neck remnant after treatment with MED alone, and partially thrombosed aneurysms.

Our study has several limitations including those inherent to a retrospective design. In addition aneurysm location is varied as is the number of devices. In order to determine the effects of intraluminal and intrasaccular flow diversion on aneurysm filling and luminal flow we plan to perform bench side studies in the near future to evaluate the effects of MED and MED+FDS and hope to provide an indication as to the optimal number and combination of devices.

\section{CONCLUSION}

The use of intraluminal and intrasaccular flow diversion appears to be an effective treatment strategy 


\section{Luminal and saccular flow diversion}

for the treatment of aneurysms that can lead to rapid aneurysm exclusion. We believe that this may provide a useful alternative strategy in large and partially thrombosed aneurysms. Further studies are required to determine the usefulness of the techniques in ruptured aneurysms as well as the optimal combination of devices.

\section{Conflict of Interests}

P. Bhogal and M. AlMatter serve as proctors and consultants for phenox.

H. Henkes is a co-founder and share-holder of phenox. The other authors report no conflict of interest.

\section{References}

1. Sourour N-A, Vande Perre S, Maria FD, Papagiannaki C, Gabrieli J, Pistocchi S, et al. Medina ${ }^{\circledR}$ Embolization Device for the Treatment of Intracranial Aneurysms: Safety and Angiographic Effectiveness at 6 Months. Neurosurgery 2018;82:155-162

2. Turk AS, Maia O, Ferreira CC, Freitas D, Mocco J, Hanel R. Periprocedural safety of aneurysm embolization with the Medina Coil System: the early human experience. J Neurointerventional Surg 2016;8:168-172

3. Aguilar Perez M, Bhogal P, Martinez Moreno R, Bäzner H, Ganslandt O, Henkes H. The Medina Embolic Device: early clinical experience from a single center. J Neurointerventional Surg 2017;9:77-87

4. Mascitelli JR, Moyle H, Oermann EK, Polykarpou MF, Patel AA, Doshi AH, et al. An update to the Raymond-Roy Occlusion Classification of intracranial aneurysms treated with coil embolization. J Neurointerventional Surg 2015;7:496-502

5. You S-H, Kong D-S, Kim J-S, Jeon P, Kim KH, Roh HK, et al. Characteristic features of unruptured intracranial aneurysms: predictive risk factors for aneurysm rupture. J Neurol Neurosurg Psychiatry 2010;81:479-484

6. Szikora I, Berentei Z, Kulcsar Z, Marosfoi M, Vajda ZS, Lee W, et al. Treatment of intracranial aneurysms by functional reconstruction of the parent artery: the Budapest experience with the pipeline embolization device. AJNR Am J Neuroradiol 2010; 31:1139-1147

7. Kadirvel R, Ding Y-H, Dai D, Rezek I, Lewis DA, Kallmes DF. Cellular mechanisms of aneurysm occlusion after treatment with a flow diverter. Radiology 2014;270:394-399

8. Fiorella D, Lylyk P, Szikora I, Kelly ME, Albuquerque FC, McDougall CG, et al. Curative cerebrovascular reconstruction with the Pipeline embolization device: the emergence of definitive endovascular therapy for intracranial aneurysms. $J$ Neurointerventional Surg 2009;1:56-65

9. Kallmes DF, Ding YH, Dai D, Kadirvel R, Lewis DA, Cloft HJ. A new endoluminal, flow-disrupting device for treatment of saccular aneurysms. Stroke J Cereb Circ 2007;38:2346-2352

10. Kallmes DF, Ding YH, Dai D, Kadirvel R, Lewis DA, Cloft HJ. A second-generation, endoluminal, flow-disrupting device for treatment of saccular aneurysms. AJNR Am J Neuroradiol 2009; 30:1153-1158
11. Pereira VM, Bonnefous O, Ouared R, Brina O, Stawiaski J, Aerts $\mathrm{H}$, et al. A DSA-based method using contrast-motion estimation for the assessment of the intra-aneurysmal flow changes induced by flow-diverter stents. AJNR Am J Neuroradiol 2013;34:808-815

12. Zhang Y, Chong W, Qian Y. Investigation of intracranial aneurysm hemodynamics following flow diverter stent treatment. Med Eng Phys 2013;35:608-615

13. Huang Q, Xu J, Cheng J, Wang S, Wang K, Liu J-M. Hemodynamic changes by flow diverters in rabbit aneurysm models: a computational fluid dynamic study based on microcomputed tomography reconstruction. Stroke 2013;44:1936-1941

14. Mut F, Raschi M, Scrivano E, Bleise C, Chudyk J, Ceratto R, et al. Association between hemodynamic conditions and occlusion times after flow diversion in cerebral aneurysms. $J$ Neurointerventional Surg 2015;7:286-290

15. Larrabide I, Geers AJ, Morales HG, Aguilar ML, Rüfenacht DA. Effect of aneurysm and ICA morphology on hemodynamics before and after flow diverter treatment. J Neurointerventional Surg 2015;7:272-280

16. Kulcsár Z, Augsburger L, Reymond P, Pereira VM, Hirsch S, Mallik AS, et al. Flow diversion treatment: intra-aneurismal blood flow velocity and WSS reduction are parameters to predict aneurysm thrombosis. Acta Neurochir (Wien) 2012;154:18271834

17. Ouared R, Larrabide I, Brina O, Bouillot P, Erceg G, Yilmaz H, et al. Computational fluid dynamics analysis of flow reduction induced by flow-diverting stents in intracranial aneurysms: a patient-unspecific hemodynamics change perspective. [published online ahead of print Feb 15, 2016] J Neurointerventional Surg 2016

18. Jing L, Zhong J, Liu J, Yang X, Paliwal N, Meng H, et al. Hemodynamic Effect of Flow Diverter and Coils in Treatment of Large and Giant Intracranial Aneurysms. World Neurosurg 2016; 89:199-207

19. Kojima M, Irie K, Fukuda T, Arai F, Hirose Y, Negoro M. The study of flow diversion effects on aneurysm using multiple enterprise stents and two flow diverters. Asian J Neurosurg 2012;7:159-165

20. Janiga G, Daróczy L, Berg P, Th?venin D, Skalej M, Beuing O. An automatic CFD-based flow diverter optimization principle for patient-specific intracranial aneurysms. J Biomech 2015;48:38463852

21. Shobayashi Y, Tateshima S, Kakizaki R, Sudo R, Tanishita K, Vinuela $F$. Intra-aneurysmal hemodynamic alterations by a selfexpandable intracranial stent and flow diversion stent: high intraaneurysmal pressure remains regardless of flow velocity reduction. J Neurointerventional Surg 2013;5(Suppl 3):iii38-42

22. Augsburger L, Farhat M, Reymond P, Fonck E, Kulcsar Z, Stergiopulos N, et al. Effect of flow diverter porosity on intraaneurysmal blood flow. Klin Neuroradiol 2009;19:204-214

23. Frölich AM, Nawka MT, Ernst M, Frischmuth I, Fiehler J, Buhk J-H. Intra-aneurysmal flow disruption after implantation of the Medina ${ }^{\circledR}$ Embolization Device depends on aneurysm neck coverage. PloS One 2018;13:e191975

24. Aguilar Perez M, Bhogal P, Martinez Moreno R, Bäzner H, Ganslandt O, Henkes H. The Medina Embolic Device: early clinical experience from a single center. J Neurointerventional Surg 2017;9:77-87

25. Bhogal P, Brouwer PA, Yeo L, Svensson M, Söderman M. The 


\section{Pervinder Bhogal, et al.}

Medina Embolic Device: Karolinska experience. Interv Neuroradiol J Peritherapeutic Neuroradiol Surg Proced Relat Neurosci 2018;24:4-13

26. Brinjikji W, Murad MH, Lanzino G, Cloft HJ, Kallmes DF. Endovascular treatment of intracranial aneurysms with flow diverters: a meta-analysis. Stroke J Cereb Circ 2013;44:442-447

27. Zhou G, Su M, Zhu Y-Q, Li M-H. Efficacy of Flow-Diverting Devices for Cerebral Aneurysms: A Systematic Review and Metaanalysis. World Neurosurg 2016;85:252-262

28. Turowski B, Macht S, Kulcsár Z, Hänggi D, Stummer W. Early fatal hemorrhage after endovascular cerebral aneurysm treatment with a flow diverter (SILK-Stent): do we need to rethink our concepts? Neuroradiology 2011;53:37-41

29. Briganti F, Leone G, Napoli M, Lauriola W, Florio F, Maiuri F. Early Fatal Hemorrhage After Endovascular Treatment of a Giant Aneurysm with Flow Diverter Device and Coils. Clin Neuroradiol 2015;25:201-205

30. Rouchaud A, Brinjikji W, Lanzino G, Cloft HJ, Kadirvel R, Kallmes DF. Delayed hemorrhagic complications after flow diversion for intracranial aneurysms: a literature overview. Neuroradiology 2016;58:171-177

31. Kallmes DF, Hanel R, Lopes D, Boccardi E, Bonafé A, Cekirge S, et al. International Retrospective Study of the Pipeline Embolization Device: A Multicenter Aneurysm Treatment Study. AJNR Am J Neuroradiol 2015;36:108-115

32. Cebral JR, Mut F, Raschi M, Scrivano E, Ceratto R, Lylyk P, et al. Aneurysm rupture following treatment with flow-diverting stents: computational hemodynamics analysis of treatment. AJNR Am J Neuroradiol 2011;32:27-33

33. Kulcsár Z, Houdart E, Bonafé A, Parker G, Millar J, Goddard
AJP, et al. Intra-aneurysmal thrombosis as a possible cause of delayed aneurysm rupture after flow-diversion treatment. $A J N R$ Am J Neuroradiol 2011;32:20-25

34. Cebral J, Ollikainen E, Chung BJ, Mut F, Sippola V, Jahromi BR, et al. Flow Conditions in the Intracranial Aneurysm Lumen Are Associated with Inflammation and Degenerative Changes of the Aneurysm Wall. AJNR Am J Neuroradiol 2017;38:119-126

35. Velioglu M, Kizilkilic O, Selcuk H, Kocak B, Tureci E, Islak C, et al. Early and midterm results of complex cerebral aneurysms treated with Silk stent. Neuroradiology 2012;54:1355-1365

36. Berge J, Biondi A, Machi P, Brunel H, Pierot L, Gabrillargues J, et al. Flow-diverter silk stent for the treatment of intracranial aneurysms: 1-year follow-up in a multicenter study. AJNR Am J Neuroradiol 2012;33:1150-1155

37. Damiano RJ, Ma D, Xiang J, Siddiqui AH, Snyder KV, Meng H. Finite Element Modeling of Endovascular Intervention Enables Hemodynamic Prediction of Complex Treatment Strategies for Coiling and Flow Diversion. J Biomech 2015;48:3332-3340

38. Lin N, Brouillard AM, Krishna C, Mokin M, Natarajan SK, Sonig A, et al. Use of coils in conjunction with the pipeline embolization device for treatment of intracranial aneurysms. Neurosurgery 2015;76:142-149

39. Martinez-Moreno R, Aguilar M, Wendl C, Bäzner H, Ganslandt O, Henkes H. Fatal Thrombosis of a Flow Diverter due to Ibuprofen-related Antagonization of Acetylsalicylic Acid. Clin Neuroradiol 2016;26:355-358

40. Phan K, Huo YR, Jia F, Phan S, Rao PJ, Mobbs RJ, et al. Metaanalysis of stent-assisted coiling versus coiling-only for the treatment of intracranial aneurysms. J Clin Neurosci Off J Neurosurg Soc Australas 2016;31:15-22 


\section{Luminal and saccular flow diversion}

\section{COMMENTARY}

Chang-Woo Ryu, MD.

Department of Radiology, Kyung Hee University

Hospital at Gangong, Seoul, South Korea

phone: +82.2 .40 .6186$

e-mail:md.cwryu@gmail.com

For last two decades, detachable coil stands unequaled as endovascular devices for the treatment of intracranial aneurysms. However, its unique position has been challenged by novel devices that were developed based on the concept of flow diversion. Flow diverter stents (FDS), such as the Pipeline Embolization Device (PED) (ev3-Covidien, Irvine, CA, USA), is constructed of a braided tubular structure that isolates blood flow away from the aneurysm sac and promotes reconstruction of the parent artery. Intrasaccular devices, such as the Woven EndoBridge (WEB, Sequent Medical, Aliso Viejo, CA, USA) or the Medina Embolic Device (Covidien/eV3, Medtronic, Dublin, Ireland), are considered new generation embolic devices that can be placed inside the aneurysmal sac to disrupt intra-aneurysmal flow; however, these devised are not yet available in Korea. ${ }^{1}$ These new devices are expected to address the shortcomings of coil embolization, such as the high recurrent rate of large aneurysms.

In addition to documenting their experiences using the MED for the treatment of intracranial aneurysms, the report by Bhogal et al. is particularly interested in the combined use of MED and FDS. ${ }^{2}$ The combined usage of MED and PDS seeks to protect against both the inflow jet and the impingement of the jet on the aneurysm wall simultaneously, thereby preventing a delayed rupture that could occur when using flowdiverters alone. ${ }^{3}$ Researchers in that report also suggested that this combined usage could overcome a limitation of the MED (i.e., the incompatibility of the spherically deployed shape of the MED in irregularly shaped aneurysms).

In Bhogal et al's study, the rate of thromboembolic complications appeared to be higher than that observed in large cohorts of patients who had undergone FDS alone. ${ }^{4}$ However, given the small number of subjects included in Bhogal et al's study, this comparison is limited. Moreover, we still do not know whether the risk of developing a thromboembolic complication is related to the combined use of MED and FDS versus other causes, such as antiplatelet resistance. Therefore, further study with a large cohort and a prospective comparison is required to demonstrate the clinical safety of the combined use of MED and FDS for the treatment of intracranial aneurysms. Additionally, costeffectiveness is another important consideration. In South Korea, indications for the use of FDS are restrictive since government health insurance does not allow the use of FED in unruptured aneurysms that are less than $15 \mathrm{~mm}$ in size. If the combined used of MED and FDS will further raise the cost incurred by the health insurance program, then the benefits afforded by the use of this technique must also prove to be costeffective before the insurance program of the Korean government would accept it.

Although the MED device has obtained European approval (i.e., has a CE marker), it does not yet enjoy the approval of the Food and Drug Administration in the United States. Therefore, its use will likely not be approved in Asian countries.1 However, considering the limitations associated with the use of coils, such as a high recanalization rate and radiation exposure related to long procedure time, we expect to document additional benefits for patients who are treated using the MED.

\section{References}

1. Jia ZY, Shi HB, Miyachi S, Hwang SM, Sheen JJ, Song YS, et al. Development of New Endovascular Devices for Aneurysm Treatment. J Stroke 2018;20:46-56

2. Bhogal P, AlMatter M, Hellstern V, Bäzner H, Ganslandt O, Henkes H, et al. The Combined Use of Intraluminal and Intrasaccular Flow Diversion for the Treatment of Intracranial Aneurysms: Report of 25 Cases. Neurointervention 2018;13:20-30

3. Aguilar Perez M, Bhogal P, Martinez Moreno R, Bazner H, Ganslandt O, Henkes H. The Medina Embolic Device: early clinical experience from a single center. J Neurointerventional Surg 2017;9:77-87

4. Potts MB, Shapiro M, Zumofen DW, Raz E, Nossek E, DeSousa KG, et al. Parent vessel occlusion after Pipeline embolization of cerebral aneurysms of the anterior circulation. J Neurosurg 2017; 127:1333-1341 